\title{
An Optimization Study of Bullwhip Effect for the Inventory in E-commerce Enterprises of Fresh Products
}

\author{
Wan Hui \\ Wuhan Technology and Business University \\ Wuhan, China \\ 108181539@qq.com
}

\author{
Wei Hua \\ Wuhan Technology and Business University \\ Wuhan, China \\ 344166747@qq.com
}

\begin{abstract}
Fresh products account for a very high share of inventory cost in the enterprises and the bullwhip effect in the supply chain has further increased the cost of the suppliers. By means of integrating theory with practice, qualitative research with quantitative research, and quantitative analysis with case study, the author conducts a systematic research on the bullwhip effect in the supply chain in enterprises of fresh products. This research concludes that the enterprises can adopt measures to weaken the bullwhip effect by improving demand forecasting, enhancing information sharing and shortening lead time, so that they can improve the management efficiency of their inventory. However, more work will be needed to measure how much benefit it may bring to the fresh enterprises to weaken the bullwhip effect in the supply chain.
\end{abstract}

Keywords- Bullwhip Effect; Fresh Products; Inventory; Supply Chain; optimization

\section{INTRODUCTION}

Since 2012, in order to win a better development in the fierce market competition, an increasing number of $E$ commerce enterprises have entered the last "battle field" of e-commerce---fresh products in hope of getting more cost reduction and profit growth. To continue their development in the new situation, these E-commerce enterprises have chosen to cooperate with their partners in the supply chain to jointly reduce the operating costs and in the supply chain, most enterprises adopt the approach of "vendor managed inventory" (VMI). However, fresh products are rather different from other products, because most of them are hard to store at normal temperature; it is not easy to maintain their original freshness and quality; and their nutritional and edible values tend to lose easily only after a short period of time. Due to fresh products' nature of freshness and characteristic of putrescibility, we should not only depend on the manufacturing link, but also do a good job at the circulation link in order to solve the quality problem of fresh products. In a word, the physical characteristics of the fresh products have become the key factor which affects the entire logistics process.

In order to effectively reduce the inventory cost, it will be of vital importance to decide a rational inventory for the fresh products and well control the bullwhip effect.

\section{THEORETICAL REVIEW}

\section{A. Relevant Concepts}

\section{1) Fresh products}

In this paper, the fresh products refer to various nutritious,clean and uncooked food which has been processed at specific temperatures. It can be understood from two aspects: broad sense and narrow sense. In the broad sense, it not only includes the fresh food after the primary process of cleaning, trimming and packaging, but also contains the raw food which was picked, slaughtered or caught just now. In the narrow sense, the fresh product refers to the food which has been cleaned, trimmed, classified, packaged and even segmented. It has met the sanitary requirement of being cooked directly or being eaten raw. In this paper, the broad sense is used.

2) Bullwhip effect

Also named as demand amplification effect, "bullwhip effect" refers to the increasing demand due to the lack of effective information sharing in the flow of information from the final customers to the original suppliers.

\section{B. Structure of Supply Chain and Bullwhip Effect}

The supply chain system mainly includes two elements: organization structure and decision structure. The organization structure mainly involves the horizontal level and vertical hierarchy of the supply chain and the position of the core enterprise. The decision structure includes demand information process, ordering strategy (order batching), price strategy (price fluctuation), inventory strategy and promotion strategy (shortage game), manufacturing strategy, information sharing strategy and the suppliers' allocation mechanism etc. The organization structure and decision structure jointly determine the actual operation situation of the supply chain, exerting great influence on the bullwhip effect in the supply chain.

\section{BULLWHIP EFFECT AND ITS EFFECT ON \\ FRESH ENTERPRISES IN THE SUPPLY CHAIN}

The market condition of fresh products is constantly changing and the author mainly discusses how bullwhip effect may affect the inventory under the condition of price fluctuation.Due to price fluctuation, the consumers tend to purchase products in advance. Therefore, their current purchase does not necessarily reflect their current demand. When the products are cheap (e.g. price discount 
or product promotion), the customers' bulk purchase is simply to meet their demand after the price gets right (or price inflation).

\section{A. Basic Hypotheses for the Model}

Generally speaking, the linear demand function and constant elastic demand function are the most frequently used functions if we need to consider the price sensitivity in the inventory-price model, particularly the demand function. Let's assume the market demand function in the $\mathrm{t}$ period as follows:

$$
D_{t}=\left(a-b \cdot p_{t}\right)+r \cdot b \cdot\left(p_{t}-\frac{\sum_{i=1}^{n} p_{t-i}}{n}\right)
$$

In this function, dt refers to the market demand; pt refers to the market price; $\{p t\}$ is the independent identically distributed sequence of random variables; $r$ indicates the customers' attention degree to the past price fluctuations; $\mathrm{a}$ and $\mathrm{b}$ are non-negative constants.

Based on the above assumption, the model sets $r \geqslant 0$. If $\mathrm{r}=0$, the market demand only depends on the price, neglecting the effect of customers, price predicting behavior on the demand under the condition of price fluctuation. If $r<1$, the negative effect of price on the demand is still predominant, even though customers' price predicting behavior may have some effect on the market demand.

The square deviation of market demand can be calculated as:

$$
\begin{aligned}
& \operatorname{Var}\left(D_{t}\right)=\operatorname{Var}\left[\left(a-b p_{t}\right)+r b\left(p_{t}-\frac{\sum_{i=1}^{n} p_{t-i}}{n}\right)\right] \\
& =\operatorname{Var}\left[-b(1-r) p_{t}-\frac{r b}{n} \cdot \sum_{i=1}^{n} p_{t-i}\right] \\
& =b^{2}(1-r)^{2} \operatorname{Var}\left(p_{t}\right)+\frac{r^{2} b^{2}}{n^{2}} \cdot \operatorname{Var}\left(\sum_{i=1}^{n} p_{t-i}\right)=b^{2}\left[(1-r)^{2}+\frac{r^{2}}{n^{2}}\right] \operatorname{Var}\left(p_{t}\right)
\end{aligned}
$$

We assume that all the enterprises in the supply chain use the model of max-min stock and that they adopt the inventory strategy and forecasting techniques that are identical with those in the above-mentioned model.

\section{B. Bullwhip Effect in Moving Average Forecasts}

We assume that the enterprises estimate their actual demand based on the method of exponential smoothing during the $\mathrm{k}$ period, therefore, the inventory demand during the lead time (supposed to be L period) can be estimated as:

$$
D_{E}=L \sum_{i=1}^{p} D_{t-i} / k
$$

The retailers' ordering quantity from the manufacturers during t period is:

$$
Q_{t}=O_{t}-O_{t-1}+D_{t-1}=\left(1+\frac{L}{k}\right) D_{t-1}-\frac{L}{k} D_{t-p-1}+z\left(\sigma_{D, t}-\sigma_{D, t-1}\right)
$$

Therefore, we can obtain the following expression:

$$
B E=\frac{\operatorname{Var}\left(Q_{t}\right)}{\operatorname{Var}\left(D_{t}\right)}=\left\{\begin{array}{l}
1+\frac{2 L}{K}+\frac{2 L^{2}}{K^{2}}, n<k \\
1+\left(\frac{2 L}{K}+\frac{2 L^{2}}{K^{2}}\right)\left[1-\frac{n r-r^{2} K}{n\left(n(1-r)^{2}+r^{2}\right)}\right], n \geq k
\end{array}\right.
$$

Forecasting
By means of exponential smoothing forecasting, the retailers predicate the market demand during the lead time as follows:

$$
D_{E}=L\left[\beta D_{t-1}+(1-\alpha) D_{E, t-1}\right]=L \sum_{k=1}^{t-1} \alpha(1-\alpha)^{k-1} D_{t-k}
$$

Then we can obtain the following expression:

$$
Q_{t}=(1+\alpha L) D_{t-1}-\alpha L D_{E, t-1}
$$

The bullwhip effect can be calculated as:

$$
B E=1+2 \alpha L+\frac{2 \alpha^{2} L^{2}}{2-\alpha}-2 L\left(1+\frac{\alpha L}{2-\alpha}\right) \frac{n \alpha r\left[1-(1-r)(1-\alpha)^{n}\right]-r^{2}\left[1-(1-\alpha)^{n}\right]}{n\left[n(1-r)^{2}+r^{2}\right.}
$$

The value of bullwhip effect $B E$ will increase significantly as the smoothing coefficient $\alpha$ increases, especially when $r$ has a small valve, namely when the customers neglect the effect of the past price fluctuations on the consumption during t period. Similarly, the increase of lead time L will also significantly enhance the bullwhip effect.

\section{FACTORS AFFECTING THE BULLWHIP EFFECT OF FRESH PRODUCTS INVENTORY}

Bullwhip effect has not only largely reduced the management efficiency of the supply chain, but also exerted huge influence on the products inventory. There are several reasons that cause the bullwhip effect of the products inventory in the fresh enterprises.

\section{A. Demand Uncertainty}

In the ever-changing and customer-oriented market, demand uncertainty is constantly a great and inevitable problem in the enterprise management.

1) Change of production plan

Specifically, demand uncertainty has two meanings: the first is demand changeability, which means the amount of raw materials for the fresh products may change as the production plan develops; the second is demand diversity, namely different types of fresh products have different demand for different raw materials. Besides, bad operations during the processing of fresh products will lead to the increase of demand for raw materials in the enterprises.

\section{2) Information sharing obstacle}

The lack of information sharing among the enterprises in different nodes also makes the enterprises unable to know the exact demand, leading to the increasing distortion effect of information.

\section{3) Price competition from substitute products}

Lower price, better quality or lower switching cost of the substitute products will force the superseded products to lower their price, resulting in the purchase demand amplification and the bullwhip effect.

\section{4 )Limitations of demand forecasting}

In the supply chain, the upstream managers tend to estimate their own demand according to the demand information from the downstream and make production plans or supply plans based on their estimation. This enclosed and step-down transmitting of demand information is the main cause of bullwhip effect. 


\section{B. Defects in the Enterprises Inventory Management}

For the enterprises that specialize in the processing of fresh products, there are strict requirements in the warranty period of the raw materials and products and the core problem is that it is difficult to control the loss. The failure in the inventory control causes the frequent problems in the material and capital flow.

1) Defects in the inventory information system

At present, many enterprises specializing in the processing of fresh products have not yet established the information transmitting system, as a result, the customers' demand information obtained by the suppliers is usually delayed or inexact, making it difficult to implement the short-term production plan.

2) Defects in inventory strategy and in batch ordering decision

At present, most of the inventory strategies of the suppliers of the fresh products are too simplified because these enterprises generally adopt the strategy of batch ordering. Due to the fixed ordering cost, batch ordering helps to save the transportation cost. However, it may lead to the increase of bullwhip effect.

3) Defects in the management during the lead time

The extension of lead time will have significant influence on the demand fluctuation during the various periods in the supply chain. The longer the lead time is, the more influence it will have on the enterprises' ordering place and safety stock. Meanwhile, it will also reduce the timeliness of demand information.

\section{Short-term Game among Enterprises}

In order to get more products and maximize their profits, the customers will play games and increase their ordering quantities. When most customers reach the equilibrium in the game, the ordering quantities of all the customers will be several times the same as their actual demand, thus producing bullwhip effect.

\section{CASE STUDY---OPTIMIZATION SCHEME OF BULLWHIP EFFECT OF FRESH PRODUCTS INVENTORY IN JSY COMPANY}

JSY Agricultural Technology Limited Company is a modern agricultural technology company with an investment of 100 million yuan. It is a professional enterprise which is based on the supply of fresh agricultural products and provides the "clean vegetables delivery" service for the urban residents by means of modern supply chain of agricultural products. In this section, the author will take this company as an example and study the bullwhip effect in its supply chain.

The reasons for the bullwhip effect in the supply chain of JSY company are mainly as follows: the demand of next period is simply estimated according to the the data from the former period, so the estimation sample is small and there is no enough effective communication with the distributors; the large number of distributors causes multiple demand forecasting; JSY manages the raw materials in a simplistic way because all the departments adopt the same purchase strategy, namely the batch ordering, which may easily lead to the alternate between inventory backlog and inventory shortage; the information at various nodes of the supply chain flows in one direction from the downstream distributors to the upstream manufacturers and it's difficult for the distributors to know about the exact information about the manufacturers, that is to say, information sharing is lacking in the supply chain; the enterprises at various nodes of the supply chain of JSY company are isolated from each other except for the maintaining of their buyer-seller relationship, therefore, they lack mutual trust; partial raw materials of JSY company are purchased from other places, so the interval between the lead time is too long; the price of the products is unstable, which may easily cause game playing among the enterprises.

In order to reduce the bullwhip effect in the supply chain, JSY has improved the entire supply chain from the following aspects.

\section{A. Enhancing Information Sharing among Various} Nodes in the Supply Chain

1) JSY establishes the EC system and actively promotes the EDI. With the help of Internet technology, all information can be rapidly transmitted among the enterprises, thus improving the trading efficiency and reducing the cost.

2) By exchanging information with the consumers directly online, JSY can effectively know about the market demand and make quick response to the changing market, thus meeting the customers' personalized requirements. On the one hand, it ensures to meet the customers' requirements and on the other hand, it helps to reduce the inventory.

3) JSY establishes the barcode system. With the barcode as the data source, JSY uses the terminal equipment to scan the barcode in order to acquire the data in order to know and control the exact status and data about the inventory and every aspect of the business immediately.

\section{B. Forming the Strategic Alliances and Reducing the Game Playing}

JSY has established the strategic partnership with the suppliers of raw materials and the distributors through the exchange of partial stock rights. This kind of strategic partnership has changed the form of information sharing and inventory management, thus reducing the bullwhip effect. Besides, JSY also restricts the variation of the distributors' ordering quantity through contracts.

\section{Shortening the Lead Time}

JSY has shortened the lead time mainly by cutting down the purchase lead time. JSY is seeking for suppliers of fresh products. This company also provides assistance in technology and equipment for the potential suppliers in the local area and evaluates the performance of these local suppliers, which lasts for half a year. In this way, time for the preparation of the raw materials is shortened. It takes only 2 days for the suppliers to complete the delivery after receiving the order, which is 2 days less than the original time duration. Therefore, time for the preparation of the raw materials is reduced by $80 \%$, improving JSY's ability to adapt itself to the changeable market. In addition, JSY 
has also reduced the inventory in order to save the management cost.

\section{Adopting the Strategy of Price Stability}

JSY has reduced the variation of customers' demand by selling products at a stable price. By eliminating the price promotion, the distributors can remove the sharp change in the demand, making the sales volume close to the actual demand. Therefore, unitary price strategy will help to produce a customer demand model which is more stable and less changeable.

\section{E. Comparison before and after the Reduction of Bullwhip Effect}

\section{1) Before the improvement}

Prior to 2013, the framework of JSY's supply chain was: the distributors gathered the ordering demand of the final consumers and provided the demand forecasting in various regions. Three major distributors were set up, in which A was responsible for gathering the customer demand in region $\mathrm{A} ; \mathrm{B}$ was for region $\mathrm{B}$ and $\mathrm{C}$ for region C. The forecasting duration lasted for 7 days. The distributors gave the demand forecasting to JSY, who transformed the demand forecasting into ordering demands and returned them to the distributors. Let's take an example, in which the production is 200 thousand. Because the suppliers are in other locality, it will take 4 days from receiving the order to completing the dilivery, exclusive of the 2 days of test duration. It will take the manufacturer 3 days to produce, 2 days to inspect and another 3 days to transport these products to the distributors in all the regions.

According to the formula of bullwhip effect, we have following expressions before the improvement:

$$
\begin{aligned}
& \mathrm{p}=7, \quad \mathrm{~L}=4+2+3+2+3=14, \quad \rho=0 \\
& B E=\frac{\operatorname{Var}\left(Q_{t}\right)}{\operatorname{Var}\left(D_{t}\right)} \geq 1+\left(2 \times 14 / 7+2 \times 14^{2} / 7^{2}\right)=13
\end{aligned}
$$

\section{2) After the improvement}

After 2013, in order to improve the operation state, JSY communicated with the customers and reduced the original 3 distributors to be 1 distributor. Besides, the original trans-regional purchase was transformed as local purchase, which largely shortened the purchase duration. The original testing procedures were integrated and all the testing was completed by one unitary testing organization, which helped to reduce the producing delay caused by non-simultaneous testing and shorten the time.The framework of JSY's supply chain after the improvement is: the distributor gathers the ordering demand of final consumers and provides the demand forecasting in various regions. The forecasting lasts for 10 days. The distributor gives the demand forecasting to JSY, who transforms the demand forecasting into ordering demands and returns them to the suppliers. The enterprises at all the nodes of the supply chain are able to get the demand and inventory information from the information center. They also upload their own ordering and inventory information to the information center. In this way, the original one-way upward transmitting turns into the two-way mutual transmitting. Moreover, it will take the suppliers only two days to complete the delivery after receiving the ordering, because they are in the same region and the operation procedures are simpler. By improving the production efficiency, the manufacturer only needs 1 day to produce, 1 day to test and 2 days to deliver the products to the distributor.

After the improvement, we can get the following expressions:

$$
\begin{aligned}
& \mathrm{p}=10, \mathrm{~L}=2+1+1+2=6, \quad \rho=0 \\
& B E=\frac{\operatorname{Var}\left(Q_{t}\right)}{\operatorname{Var}\left(D_{t}\right)} \geq 1+\left(2 \times 6 / 7+2 \times 6^{2} / 10^{2}\right)=3.4
\end{aligned}
$$

We can see from the above calculation that JSY's measures to reduce the bullwhip effect in the supply chain have produced preferable results, because the value of bullwhip effect has been decreased from 13 to 3.4. However, there is still room for improvement.

Bullwhip effect is an inherent problem in the supply chain, which significantly influences the enterprises' economic benefit. Only when all the member enterprises in the supply chain join hands, cooperate with each other and complement each other's advantages, can the bullwhip effect be reduced, thus reducing the loss in each enterprise and further improving the competitiveness of the enterprises and the supply chain as a whole.

\section{REFERENCES}

[1] Zhang Hao. Purchase Management and Inventory Control[M]. Beijing: Peking University Press, 2013.

[2] Paul H.Zipkin, trans by Song Jingsheng, Ma Changsong. Fundamentals of InventoryManagement[M] . Beijing: China Financial and Economic Publishing House, 2013.

[3] Donald J.Bowersox, David J.Closs, M.Bixby Cooper, trans by Ma Shihua, Huang Shuang. logistics management for Supply Chain[M]. Beijing: China Machine Press, 2010.

[4] Wang Daoping, Hou Meiling. Inventory Management and Control for Supply Chain[M]. Beijing: Peking University Press, 2011.

[5] Jiang Changbing, Bai Lijun, Wu Chengjian. Warehouse Management Strategy, Planning and Operation[M] . Beijing: China Supplies Press, 2010.

[6] Zhu Dapeng. Research on the Control Strategy of the Inventory of Fresh Agricultural Products[D]. Kun Ming: Yunnan University of Finance, 2012 : 53-61.

[7] Wang Lei. Coordination between Ordering, Pricing and Supply Chain of Fresh Agricultural Products where Refreshment Affects the Consumer Effectiveness[D] . Chongqing: Chongqing University, 2013 : 36-48.

[8] Wang Lei. Research on the Inventory Control Model of Cold-chain based Fresh Agricultural Products[D] . Shenyang: Shenyang University of Technology, $2010: 41-66$

[9] Chen Hong, Zhou Zongfang, Chen Jun. Inventory Replenishment Strategy Duringthe Growth Period for Fresh Agriculture Products[J]. Systems Engineering, 2010,1 (1) : 12-15.

[10] Wang Lijuan, Hou Yunxian. Inventory Control of the Weibull Distributed Fresh Agriculture Products[J]. Journal of Wuhan University (Science Edition), 2014,3 (2) : 3-5. 